\title{
Aprimoramento da Linguagem Científica de Discentes da Licenciatura com Foco na Formação Profissional
}

\author{
Naissa Maria Silvestre Dias ${ }^{1 *}$; Rosebelly Nunes Marques ${ }^{2 *}$ \\ ${ }^{1}$ CENA/USP, Laboratório de Biogeoquímica Ambiental \\ 2ESALQ/USP, Departamento de Economia, Administração e Sociologia
}

* Autoras para correspondência: nsdias@cena.usp.br; rosebelly.esalq@usp.br

\section{RESUMO}

As Diretrizes Curriculares Nacionais dos cursos de graduação em Engenharia Agronômica e em Engenharia Florestal demandam profissionais nas respectivas áreas com sólida formação científica. Visando ao aprimoramento das habilidades pessoais e profissionais esperadas de alunos egressos dos cursos citados, referentes à linguagem científica, utilizaram-se artigos científicos como recurso didático. No presente trabalho, apresentam-se e discutem-se os resultados de atividades com quatro artigos nas áreas de prática pedagógica, educação ambiental, experimentação e saberes técnicos, sendo estes relacionados aos temas das aulas ministradas. Exigiu-se a leitura prévia dos textos, com análise individual por escrito; realizaram-se discussões em grupos; e, por conseguinte, uma socialização das ideias envolvendo todos os alunos, tendo a docente como mediadora. Nesse momento, houve postura crítica sobre os assuntos discutidos, como a qualidade, o conteúdo, a linguagem adotada e até mesmo sobre a ética identificada nos artigos. A maturidade dos alunos também foi percebida na produção escrita, demonstrando que o resgate do conhecimento prévio, somado às discussões nas aulas ministradas anteriormente, proporciona a participação ativa, resultando numa prática conscientizadora e crítica. Nesse sentido, os alunos foram protagonistas no processo de construção de seus próprios conhecimentos, melhoraram sua linguagem científica e desenvolveram a autonomia.

Palavras-Chave: Saberes Científicos; Participação Ativa; Autonomia.

\begin{abstract}
The National Gurriculum Guidelines for Agricultural and Forestry Engineering degree course require professional graduates in their respective areas with solid scientific background. In order to improve the personal and professional skills expected of alumni of the above courses, referring to scientific language, they used scientific articles, as a teaching resource. In this manuscript we presented and discussed results of activities with four scientific articles for each following area: pedagogical practice, environmental education, experimentation and technical knowledgement, which are related to the themes of classes taught. Prior reading of texts was demanded with individual written analysis, followed by discussion groups and therefore socialization of ideas involving all students, with the teacher as a mediator. In this moment, there were critical stances on the issues discussed as well as the quality, the contents, the language and even the ethics adopted in the articles were identified. The maturity of the students was also seen in the written production, showing that the recovery of prior knowledge added to the class discussion given above, it provides the active participation, resulting in conscientization and critical practice. In this sense, the students were protagonists in the building process of their own knowledgement, improved their scientific language and developed autonomy.
\end{abstract}

Keywords: Scientific Knowledge; Active Participation; Autonomy.

\section{Introdução}

As Diretrizes Curriculares Nacionais dos cursos de graduação em Engenharia Agronômica e em Engenharia Florestal, descritas nas Resoluções n. 1 e 3 , de 2 de fevereiro de 2006, respectivamente, demandam profissionais formados nas respectivas áreas com sólida formação científica. Sendo assim, espera-se que esses profissionais utilizem e 
desenvolvam tecnologias, que englobem tanto o aspecto social quanto científico, atuando de forma crítica na solução de problemas (BRASIL, 2006). As diretrizes curriculares para os cursos de graduação insistem em práticas de estudo que promovam uma progressiva autonomia profissional e intelectual do aluno.

Diante disso, Zucco et al. (1999) defendem a criação de um modelo de curso superior em que os professores ensinem os estudantes a aprenderem coisas e soluções, isto é, que eles assumam um papel emancipatório no processo de aprendizagem.

$\mathrm{O}$ uso de artigos científicos pode auxiliar nesse processo emancipatório, promovendo a leitura, a interpretação de textos e a análise crítica de tais materiais, habilitando, assim, os alunos na propagação de saberes científicos e na expressão de resultados de futuras pesquisas utilizando correta linguagem científica (SANTOS \& QUEIROZ, 2007).

Considerando a importância da linguagem científica na formação profissional do aluno da Licenciatura, o objetivo deste estudo foi identificar e aprimorar o domínio da linguagem científica por alunos de graduação.

\section{Desenvolvimento}

Visando ao aprimoramento das habilidades pessoais e profissionais esperadas de alunos egressos da universidade referentes à linguagem científica, utilizaram-se artigos científicos como recurso didático, no contexto da disciplina de Instrumentação para o Ensino das Ciências Agrárias, oferecida a alunos de graduação em Engenharia Agronômica e Florestal. No presente trabalho, apresentam-se e discutem-se os resultados de atividades com quatro artigos nas áreas de: (1) prática pedagógica, (2) educação ambiental, (3) experimentação; e (4) saberes técnicos, sendo estes relacionados com os temas das aulas ministradas.

A escolha de cada texto foi embasada no conjunto de informações que, além de promover a discussão e a postura científico-crítica desses alunos, estava direcionado ao conteúdo programático da disciplina apresentado em seu plano de ensino. O texto 1 , que versava sobre prática pedagógica, apresentou um panorama teórico sobre aspectos a considerar dentro do ensino, traduzidos de forma sintética em: O que ensinar? Como ensinar? E para quem?, valorizando o papel do professor nesse processo produtivo. $\mathrm{O}$ texto 2 , sobre saberes técnicos, foi direcionado para o campo de atuação/formação dos alunos da licenciatura em Ciências Agrárias: possibilitou discutirem-se a essência dos conteúdos e as práticas nessa área. Já os textos 3 e 4 apresentavam ideias relacionadas à aplicação mais prática $\mathrm{e}$ ampla, promovendo discussões sobre metodologia, no caso do experimento, e também sobre a proposta de interdisciplinaridade.

Inicialmente, exigiu-se a leitura prévia dos textos, com análise individual e destaque de trechos com que concordavam e discordavam. Tal etapa gerou uma produção escrita. Seguiu-se com discussões em grupos de três alunos e, por conseguinte, depois de formadas as opiniões, com uma socialização das ideias envolvendo todos os alunos, tendo a docente como mediadora. Nesse momento, verificou-se a postura crítica sobre os assuntos discutidos, como a qualidade, o conteúdo, a linguagem adotada e até mesmo sobre a ética identificada nos artigos. Depois das análises, individuais e em grupo, dos textos, os alunos responderam, em grupo, quais as ações que desenvolveriam colocando-se no lugar dos autores desses textos. Observou-se uma postura bastante profissional e ética nas colocações, quando discordavam dos procedimentos adotados pelos autores. Um exemplo foi a reorganização do procedimento da atividade envolvendo o $\mathrm{pH}$ dos solos: na concepção deles, poderia haver mudanças proporcionando efeitos visuais mais efetivos, consequentemente melhorando a aprendizagem dos conceitos. Outro aspecto de destaque foi a maturidade dos alunos ao perceberem o posicionamento intransigente dos autores, que desconsideram as limitações das atividades relatadas e enaltecem o próprio trabalho diversas vezes no decorrer do texto. Essa maturidade dos alunos também foi notada na produção escrita na primeira etapa do trabalho, demonstrando que o resgate do conhecimento prévio, somado às discussões nas aulas ministradas anteriormente, proporciona a participação ativa, resultando numa prática conscientizadora e crítica. 
É importante ressaltar que se criou um ambiente de aprendizagem efetiva, favorável às discussões pertinentes, em que o aluno se percebeu como parte desse ambiente e importante nesse contexto.

\section{Conclusão}

Os alunos foram protagonistas no processo de construção de seus próprios conhecimentos, melhoraram sua linguagem científica e desenvolveram a autonomia. Sentiram-se encorajados a escrever seus trabalhos em revistas científicas, pois se sentiram capazes. Relataram que muitas atividades são realizadas e poderiam ser socializadas em âmbito científico.

\section{Referências Bibliográficas}

BRASIL. Ministério da Educação. Conselho Nacional de Educação. "Institui as Diretrizes Curriculares Nacionais para o Gurso de Graduação em Engenharia Agronômica ou Agronomia. Resolução n. 1, de 2 de fevereiro de 2006". LEX: Diário Oficial da União, Seção I, pp. 33-34, fev. 2006.

SANTOS; G. R. \& QUEIROZ, S. L. "Leitura e Interpretação de Artigos Científicos por Alunos de Graduação em Química”. Ciência e Educação, Bauru, vol. 13, n. 2, 2007, pp. 193-209.

ZUCCO, C.; PESSINE, F. B. T. \& ANDRADE, J. B. "Diretrizes Curriculares para os Cursos de Química". Química Nova, São Paulo, vol. 22, n. 3, 1999, pp. 454-461. 